\title{
RESEARCH
}

Open Access

\section{The atherogenic index (ATH index) as a potential predictive marker of idiopathic sudden sensorineural hearing loss: a case control study}

Anastasiya M. Kaneva ${ }^{1 *}$ (D, Yury K. Yanov², Svetlana G. Bojko ${ }^{3}$, Olga E. Kudryavykh², Natalya N. Potolitsyna', Evgeny R. Bojko ${ }^{1}$ and Jon $\varnothing$. Odland ${ }^{4}$

\begin{abstract}
Background: The importance of blood lipids in the pathogenesis of sudden sensorineural hearing loss (SSNHL) is widely discussed in the literature. However, the published results that hyperlipidaemia causes hearing problems are contradictory. The objective of this study was to establish whether increased lipid levels affect the risk of idiopathic SSNHL.

Methods: A case-controlled study was conducted of 27 patients with idiopathic SSNHL and 24 healthy control subjects. All of the subjects underwent complete audiological examination. The plasma levels of total cholesterol (TC), triglycerides (TG), high-density lipoprotein cholesterol (HDL-C), apolipoprotein (apo) A-I, apoB and apoE were measured with commercially available kits (Chronolab Systems, Spain). Several clinical ratios and indices of lipid metabolism were calculated.

Results: Detailed analysis of lipid metabolism in patients with idiopathic SSNHL has shown that disturbances in auditory function are associated with increased atherogenicity of the lipid profile. However, there were no significant differences in the conventional parameters of lipid metabolism (TC, TG and HDL-C) between patients with idiopathic SSNHL and subjects in the control group. Higher values of the apoB/apoA-I ratio, atherogenic index of plasma (AIP) and atherogenic index (ATH index) in patients with SSNHL indicated increased atherogenicity of the lipid profile. Binary logistic regression analysis showed that of these three indices, only higher values of the ATH index were significantly associated with an increased risk of idiopathic SSNHL.
\end{abstract}

Conclusions: The ATH index can be used as a marker indicating the risk of idiopathic SSNHL when the conventional lipid indices are still normal.

Keywords: Sensorineural hearing loss, Lipids, apoB/apoA-I ratio, Atherogenic index of plasma (AIP), Atherogenic index (ATH index)

\footnotetext{
* Correspondence: amkaneva@mail.ru

${ }^{1}$ Institute of Physiology of Komi Science Centre of the Ural Branch of the Russian Academy of Sciences, FRC Komi SC UB RAS, 50 Pervomayskaya str, Syktyvkar 167982, Russia

Full list of author information is available at the end of the article
}

(C) The Author(s). 2019 Open Access This article is distributed under the terms of the Creative Commons Attribution 4.0 International License (http://creativecommons.org/licenses/by/4.0/), which permits unrestricted use, distribution, and reproduction in any medium, provided you give appropriate credit to the original author(s) and the source, provide a link to the Creative Commons license, and indicate if changes were made. The Creative Commons Public Domain Dedication waiver (http://creativecommons.org/publicdomain/zero/1.0/) applies to the data made available in this article, unless otherwise stated. 


\section{Background}

Sudden sensorineural hearing loss (SSNHL) is typically defined as a rapid hearing loss of at least $30 \mathrm{~dB}$ in 3 contiguous audiometric frequencies within 3 days [1]. It is characterized by sudden onset, and, within a few hours, it reaches its maximum peak. SSNHL can have varying causes and aetiologies. It is estimated that a cause is identified in only $10 \%$ of patients with SSNHL [2]. The diagnosis of idiopathic SSNHL can be made definitively when no causes are found [3]. To date, there have been several proposed mechanisms for idiopathic SSNHL, which include viral infections [4]; immune-mediated mechanisms [5]; damage, including noise trauma [6]; inflammatory events [7]; otologic and metabolic diseases [8]; ototoxic chemicals and drugs [9]; head trauma [10]; neoplasms [11]; and vascular disturbances [3]. Vascular abnormalities are one of the two most common theories for the aetiology of idiopathic SSNHL; the other is inflammatory reactions (most often viral) [12]. According to vascular aetiology theories, the sudden loss of hearing could result from an acute vascular haemorrhage, occlusion by emboli, vascular diseases, vasospasms, or changes in blood viscosity [4]. Vascular damages may result in cochlear ischaemia and hypoxia [13].

The cochlea is an end organ, which is metabolically dependent on a nutrient and oxygen supply to maintain its normal physiological function. It is very sensitive to alterations in blood circulation [14]. Cochlear ischaemia is considered to be one of the most important causes of idiopathic SSNHL [15]. Hyperlipidaemia may contribute to cochlear ischaemia due to increased blood viscosity. Increased blood viscosity may decrease inner ear blood supply and cause inner ear damage [16]. Moreover, lipid metabolic disorders can lead to lipid deposits in cochlear hair cells and damage to cochlear neural cells, followed by impeded neural transduction [17].

Associations between hearing and blood lipid levels have been the focus of scientific inquiry for more than 50 years $[18,19]$. In 1965, Rosen was the first to demonstrate epidemiologically that hyperlipidaemia can be a cause of auditory dysfunction. At present, there are multiple clinical and animal studies that support a relationship between hyperlipidaemia and hearing loss. Hyperlipidaemia is frequently observed in patients with idiopathic SSNHL [20, 21]. In turn, patients with hyperlipidaemia show poor hearing levels at high frequencies $[16,22]$. Moreover, hearing loss associated with hyperlipidaemia tends to improve with diet control and antilipemic therapy [23, 24]. Data from animal studies have shown that diet-induced hyperlipidaemia causes structural and functional changes in the inner ear and that these changes are associated with hearing loss in a time-dependent manner $[13,14,25]$. However, the relationship between hyperlipidaemia and idiopathic SSNHL is not universally accepted. There are findings from other studies that do not support the assertion that dyslipidaemia is a risk factor for idiopathic SSNHL [26, 27].

The aim of this case-control study was to evaluate the relationship between blood lipid levels and the prevalence of idiopathic SSNHL.

\section{Materials and methods Participants}

A total of 27 patients (males; mean age of 39.7 years ranging from 27 to 51 years) affected by idiopathic SSNHL were included in the study. The exclusion criteria for idiopathic SSNHL patients were as follows: acute inflammation, infection, autoimmune disorders, fluctuating cochlea-vestibular dysfunction suggestive of endolymphatic hydrops (history of vertigo with either fluctuating hearing loss, aural pressure or episodic tinnitus preceding the idiopathic SSNHL episode); a history of otologic surgery; head and/or neck trauma or barotrauma in the 10 weeks prior to idiopathic SSNHL diagnosis; otitis media; neurologic disorders that predispose a patient to deafness; recent use of ototoxic medications; neoplasm within the previous two years; or other major diseases (such as heart failure, systemic hypertension, severe lung disease, or liver or renal dysfunction). All patients had a negative history of familial deafness.

Normal subjects (24 males; mean age of 32.3 years ranging from 25 to 47 years) without a history of hearing loss or autoimmune, metabolic or circulatory diseases were included as control group. The control subjects had normal bilateral hearing (audiometric values in normal ranges according to age) and no history of cardiovascular diseases.

All participants were informed about the aim of the study and gave written informed consent. The investigation was approved by the local ethics committee and performed in accordance with the Declaration of Helsinki. This study was conducted in the Consultative and Diagnostic Center. In all subjects, systemic physical examinations, detailed otological examinations, audiological evaluations and biochemical studies were carried out.

\section{Hearing evaluation}

All of the subjects underwent a standard evaluation that consisted of pure-tone audiometry, speech discrimination tests, impedance audiometry, tympanometry, acoustic reflex tests and magnetic resonance imaging. Pure tone and speech audiometry were carried out by an audiometer (MADSEN Itera, GN Otometrics, Denmark), and all the tests were carried out by the same speech and hearing therapist. The audiometer was installed in a sound-attenuated booth. Air and bone conduction at frequencies of $125 \mathrm{~Hz}, 250 \mathrm{~Hz}, 500 \mathrm{~Hz}, 1 \mathrm{kHz}, 2 \mathrm{kHz}, 4$ 
$\mathrm{kHz}$, and $8 \mathrm{kHz}$ were evaluated. Audiometry was performed using a standardized protocol. Impedance audiometry was performed using an audiometer (AZ26, Interacoustics, Denmark). Tympanometry was performed to help exclude middle ear disease.

\section{Lipid measurements}

Venous blood samples were collected from patients and control subjects after at least $12 \mathrm{~h}$ of fasting for the evaluation of plasma lipids. The samples were collected into vacutainer tubes containing heparin as an anticoagulant. Blood samples were centrifuged, and plasma was transferred to Eppendorf microcentrifuge tubes and stored at $-40{ }^{\circ} \mathrm{C}$ until further analysis.

Plasma total cholesterol (TC), triglycerides (TG) and high-density lipoprotein cholesterol (HDL-C) concentrations were measured using an enzymatic method with commercially available kits (Chronolab Systems, S.L., Barcelona, Spain). HDL-C concentration was determined by assaying the cholesterol in the supernatant obtained after the precipitation of apolipoprotein (apo) B-containing lipoproteins with phosphotungstate/magnesium chloride. Plasma apoA-I, apoB and apoE levels were measured using an immunoturbidimetric method with commercially available kits (Chronolab Systems, S.L., Barcelona, Spain). The samples were analysed immediately after thawing at $37^{\circ} \mathrm{C}$ in a thermostatic bath. The absorbance of all samples was measured on the Powerwave 200 automated spectrophotometer (Bio-Tek Instruments, USA). The measurement of each sample was carried out in duplicate, and the mean was calculated.

Low density lipoprotein cholesterol (LDL-C) concentration was calculated according to Friedewald's formula [28]. Several clinical indicators of lipid metabolism were computed, including the TC/HDL-C and apoB/apoA-I ratios, atherogenic index of plasma (AIP), and atherogenic index (ATH index). AIP was calculated as a logarithm of the ratio of the molar concentration $(\mathrm{mmol} / \mathrm{l})$ of TG to HDL-C (i.e., log [TG/HDL-C]) [29]. The ATH index was calculated by the following equation: $\mathrm{ATH}$ index $=((\mathrm{TC}-\mathrm{HDL}-\mathrm{C}) *$ apoB $) /($ HDL-C*apoA-I $)[30]$.

\section{Statistical analysis}

All continuous variables are presented as the median and interquartile range (25th and 75th percentiles) and compared using the Mann-Whitney test. Categorical data are shown as percentages and compared using the Chi square test. Binary logistic regression was used to assess the associations between variables and idiopathic SSNHL, and odds ratios with their 95\% confidence intervals were calculated. The statistical analysis was performed using Statistica 8.0 (Statsoft, Tulsa, USA). A value of $p<0.05$ was considered statistically significant.

\section{Results}

The results of pure-tone audiometry in the study subjects are displayed in the form of an audiogram (Fig. 1). This audiogram shows that hearing in control subjects

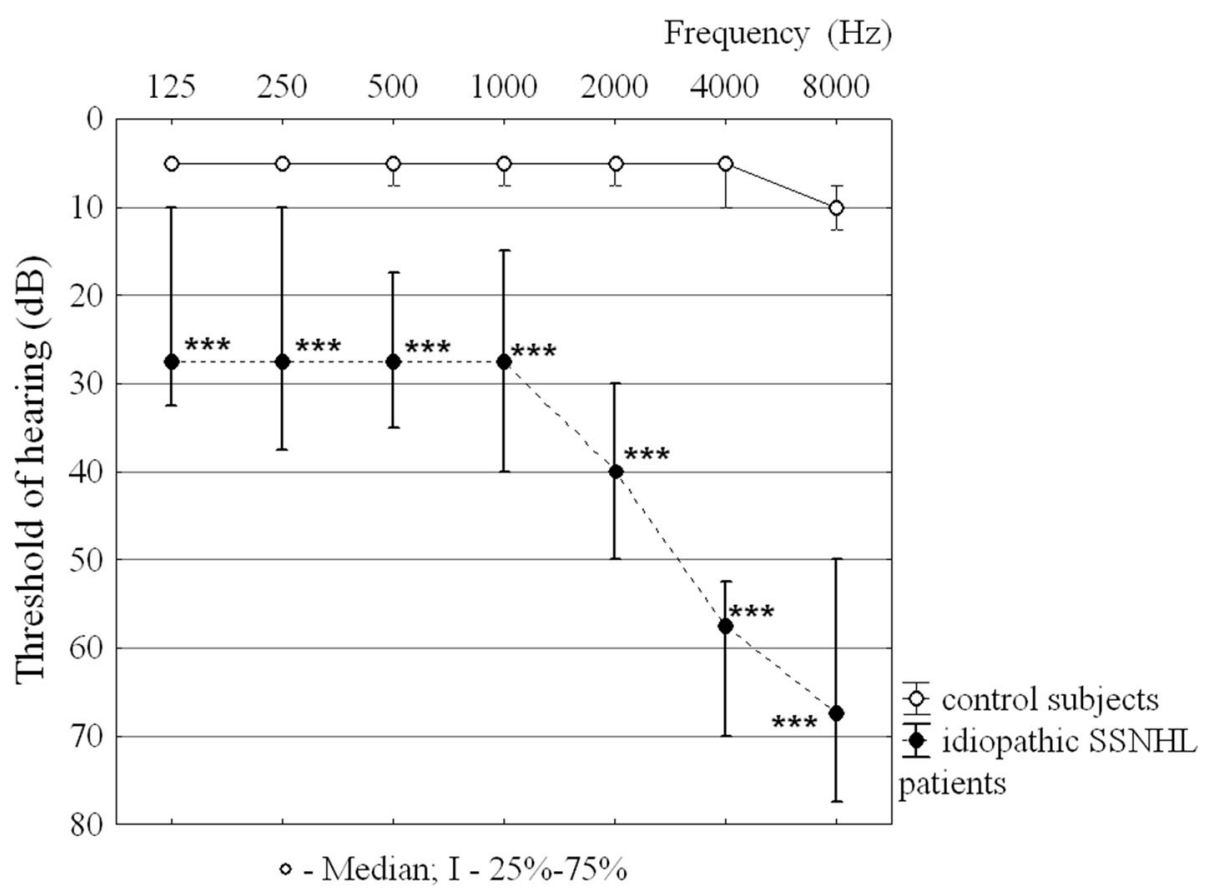

Fig. 1 Pure-tone audiograms for idiopathic SSNHL patients and control subjects. Audiogram for control subjects denotes the average hearing thresholds of both ears. Audiogram for idiopathic SSNHL patients denotes the average hearing thresholds of the poorer hearing ear 
was within normal limits $(5-10 \mathrm{~dB})$. Patients with idiopathic SSNHL had thresholds that were 20 to $60 \mathrm{~dB}$ higher than the thresholds for subjects with normal hearing at all frequencies. Severe hearing loss in patients with idiopathic SSNHL was observed at high frequencies $(4 \mathrm{kHz}$ and $8 \mathrm{kHz})$. There is no difference between the air conduction and the bone conduction thresholds in patients with idiopathic SSNHL.

No significant differences between patients with idiopathic SSNHL and control subjects in TC, TG and HDL-C levels were observed (Table 1). The number of subjects with deviations from the reference values for TC, TG and HDL-C levels in the study groups was similar (Table 2). There were no significant differences in the calculated LDL-C concentration and TC/HDL-C ratio between patients with idiopathic SSNHL and control subjects.

Meanwhile, the plasma levels of apoA-I and apoB were significantly different in patients with idiopathic SSNHL compared with control subjects (Table 1). Although the apoA-I levels decreased by only $26.8 \%$ ( $p$ $=0.031)$ and the apoB concentrations increased by only $23.6 \%(p=0.048)$ in patients with idiopathic SSNHL, the apoB/apoA-I ratio changed considerably. The median value of the apoB/apoA-I ratio in patients with idiopathic SSNHL exceeded the reference value and was 2 times higher than that of control subjects. The plasma levels of apoE did not differ significantly between the study groups.

Patients with idiopathic SSNHL were also characterized by higher AIP $(p=0.007)$ (Table 1$)$, although the number of subjects with unfavourable AIP did not differ between the study groups (Table 2). The most significant difference between patients with idiopathic SSNHL and control subjects was observed for the
ATH index (Table 1). The median value (25\%; 75\%) of ATH index in patients with idiopathic SSNHL was two times higher $(2.63(1.42,3.46))$ than that of control subjects $(1.31(0.64,1.63))$. Moreover, ATH index values higher than the reference value were observed in $29.6 \%$ of patients with idiopathic SSNHL, whereas there were no subjects with high ATH index values in control subjects (Table 2).

Binary logistic regression models were used to evaluate the associations between the risk for idiopathic SSNHL and increased values of the apoB/apoA-I ratio, AIP and ATH index (Table 3). The apoB/apoA-I ratio and AIP were not associated with idiopathic SSNHL. Meanwhile, subjects with unfavourable ATH index values had a more than 4 times higher risk of idiopathic SSNHL.

\section{Discussion}

The comparative analysis of plasma lipids in healthy subjects and patients with idiopathic SSNHL showed that auditory dysfunction was associated with an increase in lipid profile atherogenicity. In general, our finding is consistent with the results of other studies [16, 31]. However, these studies reported the relationship between SSNHL and the conventional lipid indices such as TC, HDL-C, LDL-C, TG and TC/HDL-C, whereas we found no significant differences between the study groups in these indices. The increase in lipid profile atherogenicity in patients with idiopathic SSNHL was indicated by a change in apoA-I and apoB levels and an increase in the apoB/apoA-I ratio, AIP and ATH index. To date, the apolipoprotein profile in patients with SSNHL has not been studied. There is only one study indicating increased apoB level in patients with SSNHL [32]. Therefore, the importance of the apoB/apoA-I ratio, AIP and ATH index as possible markers of SSNHL

Table 1 Plasma lipid profiles in idiopathic SSNHL patients and control subjects

\begin{tabular}{llll}
\hline Variable & \multicolumn{1}{c}{$\begin{array}{l}\text { Control subjects } \\
n=24\end{array}$} & Idiopathic SSNHL patients $n=27$ & 0.168 \\
\hline TC, mmol/L & $4.09(3.61 ; 4.63)$ & $4.26(3.84 ; 5.00)$ & 0.234 \\
TG, mmol/L & $1.02(0.79 ; 1.20)$ & $1.23(0.81 ; 1.76)$ & 0.129 \\
HDL-C, mmol/L & $1.39(1.12 ; 1.80)$ & $1.36(0.93 ; 1.51)$ & 0.199 \\
LDL-C, mmol/L & $1.92(1.34 ; 2.91)$ & $2.55(1.87 ; 3.18)$ & 0.097 \\
TC/HDL-C & $2.61(2.05 ; 3.91)$ & $3.59(2.44 ; 4.33)$ & $\mathbf{0 . 0 3 1}$ \\
apoA-I, mg/dL & $164.0(104.0 ; 193.0)$ & $120.0(83.0 ; 143.0)$ & $\mathbf{0 . 0 4 8}$ \\
apoB, mg/dL & $89.0(70.0 ; 100.0)$ & $110.0(80.0 ; 162.0)$ & $\mathbf{0 . 0 0 9}$ \\
apoB/apoA-I & $0.49(0.42 ; 0.82)$ & $1.00(0.63 ; 1.57)$ & 0.930 \\
apoE, mg/dL & $2.65(1.87 ; 2.99)$ & $2.43(1.65 ; 3.46)$ & $\mathbf{0 . 0 0 7}$ \\
AlP & $-0.17(-0.24 ;-0.06)$ & $0.01(-0.12 ; 0.14)$ & $<\mathbf{0 . 0 0 1}$ \\
ATH index & $1.31(0.64 ; 1.63)$ & $2.63(1.42 ; 3.46)$ & \\
\hline
\end{tabular}

Data are presented as the median and interquartile range (25th and 75 th percentile). ${ }^{1}$ Mann-Whitney $(U)$ test was used to estimate differences between the groups

$p$-values $<0.05$ are shown in boldface type 
Table 2 Number of participants for each lipid variable defined by reference values in idiopathic SSNHL patients and control subjects

\begin{tabular}{|c|c|c|c|c|}
\hline \multirow[t]{2}{*}{ Variable } & \multirow{2}{*}{$\begin{array}{l}\text { Reference } \\
\text { range }\end{array}$} & \multicolumn{2}{|l|}{ Number of subjects } & \multirow[t]{2}{*}{$p$ value } \\
\hline & & control subjects $(n=24)$ & idiopathic SSNHL patients $(n=27)$ & \\
\hline $\mathrm{TC}, \mathrm{mmol} / \mathrm{L}^{\mathrm{a}}$ & $<5.2$ & 0 & $4(14.8)$ & 0.149 \\
\hline $\mathrm{TG}, \mathrm{mmol} / \mathrm{L}^{\mathrm{a}}$ & $<1.7$ & $2(8.3)$ & $7(25.9)$ & 0.202 \\
\hline $\mathrm{HDL}-\mathrm{C}, \mathrm{mmol} / \mathrm{L}^{\mathrm{a}}$ & $<1.0$ & $1(4.2)$ & $7(25.9)$ & 0.081 \\
\hline $\mathrm{LDL}-\mathrm{C}, \mathrm{mmol} / \mathrm{L}^{\mathrm{a}}$ & $<2.6$ & $7(29.2)$ & $13(48.1)$ & 0.272 \\
\hline $\mathrm{TC} / \mathrm{HDL}-\mathrm{C}^{\mathrm{b}}[40]$ & $<4.5$ & $3(12.5)$ & $6(22.2)$ & 0.689 \\
\hline apoA-I, mg/dL b $[41]$ & $>120$ & $7(29.2)$ & $13(48.1)$ & 0.272 \\
\hline apoB, mg/dL ${ }^{b}[42]$ & $<120$ & $2(8.3)$ & $11(40.7)$ & 0.020 \\
\hline apoB/apoA-I ${ }^{b}[43]$ & $<0.9$ & $4(16.7)$ & $15(55.6)$ & 0.010 \\
\hline apoE, mg/dL b ${ }^{\mathrm{b}}[44]$ & $>2.7$ & $13(54.2)$ & $13(48.1)$ & 0.882 \\
\hline AIP $^{\mathrm{b}}[29]$ & $<0.11$ & $1(4.2)$ & $7(25.9)$ & 0.081 \\
\hline ATH index ${ }^{b}[30]$ & $<4.5$ & 0 & $8(29.6)$ & $<0.033$ \\
\hline
\end{tabular}

Data are presented as the number (percentage) of subjects. ${ }^{1}$ Chi-square $\left(x^{2}\right)$ test was used to estimate differences between the groups. ${ }^{\text {a }}$ Reference ranges based on the NCEP ATP III Classifications [45]. ${ }^{\mathrm{b}}$ Reference ranges taken from Refs. [29, 30, 40-44]

$p$-values $<0.05$ are shown in boldface type

has not yet been established. Nevertheless, we believe that the increased values of the apoB/apoA-I ratio, AIP and ATH index in patients with idiopathic SSNHL compared with control subjects against a background of similar concentrations of traditional lipids can be considered early markers of atherogenic changes in the lipid profile. We have previously shown that the apoB/apoA-I ratio is a sensitive marker of atherogenic risk even in the subjects with normolipidaemia [33].

The effects of hyperlipidaemia on hearing function are related to the features of inner ear circulation. The cochlea is metabolically a very active organ that depends on a steady supply of nutrients and oxygen from its vasculature to maintain homeostasis [34]. At the same time, the cochlea is supplied by a terminal capillary bed and is not able to form collateral vessels, which could restore blood flow following microvascular disturbances. Therefore, the cochlea has a high sensitivity to minimal blood flow reductions, leading to tissue ischaemia and hypoxia [3, $16,35]$. In addition, cochlear blood flow depends on arterial blood pressure and cerebral circulation [36]. These features increase the risk of both functional impairments and sclerotic changes in the artery. It has been established that even a slight deterioration in the blood

Table 3 Results of binary logistic regression analysis showing associations between the apoB/apoA-I ratio, AIP, ATH index and risk of idiopathic SSNHL $(n=27)$

\begin{tabular}{llll}
\hline Independent variables & Odds ratio & $95 \%$ Confidence interval & $p$ value \\
\hline apoB/apoA-I & 0.91 & $0.17-4.91$ & 0.908 \\
AIP & 1.53 & $0.02-151.8$ & 0.851 \\
ATH index & 4.25 & $1.32-13.7$ & $\mathbf{0 . 0 1 3}$
\end{tabular}

Data are presented as the odds ratio and $95 \%$ confidence interval $p$-values $<0.05$ are shown in boldface type supply of the cochlea can lead to ischaemic damage to this organ. Histological changes in the cochlea (vascular stripe and organ of Corti) in guinea pigs were already observed after 3 months of being on a hyperlipidemic diet [37].

The negative effect of hyperlipidaemia on microcirculation lies in the fact that it affects the rheological properties of blood, the composition of membrane lipids, the protein-lipid interactions in membrane structures and the activities of membrane-bound enzymes. Moreover, with an elevation of blood lipids, lipids can attach to the surface of erythrocytes and platelets, which reduces the charge-carrying capability of erythrocytes and enhances the adhesion between cells. The increased cholesterol content in erythrocytes also affects their deformation and oxygen-carrying capacity [25, 35]. Such changes make it more difficult for the erythrocyte to travel through microcirculation. Therefore, inner ear tissues with high metabolic requirements may show altered metabolic activity in the presence of hyperlipidaemia due to reduced oxygen availability.

In our study, most patients with idiopathic SSNHL did not have hyperlipidaemia. At the same time, patients with idiopathic SSNHL exhibited higher values of the apoB/apoA-I ratio, AIP and ATH index compared with control subjects, which indicates an imbalance between atherogenic and antiatherogenic lipoproteins in the plasma and changes in lipoprotein particle size. The maintenance of the optimal balance between low density lipoproteins (LDL) and high density lipoproteins (HDL), which carry out the transport of cholesterol to peripheral tissues with its subsequent arterial internalization and reverse transport to the liver, is important in preventing atherosclerosis. With a predominance of $\mathrm{LDL}$, 
an accumulation of LDL within the vessel wall intima begins, which leads to local oxidative modification of LDL [38]. The qualitative composition of lipoproteins also influences atherogenesis. According to the results of a prospective study, the presence of small dense LDL particles was associated with a 3.6-fold increase in the risk of ischaemic heart disease independent of LDL-C levels [39]. Thus, our results showing higher values of lipid indices in patients with idiopathic SSNHL compared with control subjects indicate the possibility of an effect of lipid profile atherogenicity on the risk of idiopathic SSNHL. Moreover, our data could explain the contradictory results regarding the association between hyperlipidaemia and hearing problems. A lack of a relationship between blood lipid levels and SSNHL was observed in studies in which the assessments of lipid profile were made by the conventional lipid indices without a detailed evaluation of atherogenicity. Whereas our results indicated a high sensitivity of the inner ear vessels to even insignificant changes in the lipid profile. This feature agrees with the view that atherosclerosis in the inner ear vessels precedes atherosclerosis in other vessels [31].

Binary logistic regression analysis showed that among the three calculated indices, only higher values of the ATH index were significantly associated with an increased risk of idiopathic SSNHL. The ATH index is a compound index of lipid metabolism and is calculated by using values of both lipids and apolipoproteins. Thus, the ATH index is an informative marker that allows an integrated evaluation of the lipid profile to be carried out. Therefore, we suggest that the ATH index can be used for the assessment of the risk of idiopathic SSNHL, since it is established that the risk of idiopathic SSNHL tends to increase as the number of cardiovascular risk factors increases [22]. Moreover, the determination of the ATH index in patients with idiopathic SSNHL will allow the selection of the adequate treatment for this pathology. Clinical studies have shown that SSNHL associated with hyperlipidaemia is treatable with timely and effective treatments $[23,24]$.

\section{Conclusion}

The ATH index is a marker indicating the risk of idiopathic SSNHL. The ATH index allows us to detect abnormalities in lipid metabolism during initial stages when the conventional lipid indices are still normal. The values of the ATH index can be useful for the overall evaluation of lipid profile atherogenicity in patients with idiopathic SSNHL and choice of adequate treatments.

\section{Abbreviations}

AIP: Atherogenic index of plasma; Apo: Apolipoprotein; ATH: Atherogenic index; HDL: High density lipoprotein; HDL-C: High density lipoprotein cholesterol; LDL: Low density lipoprotein; LDL-C: Low density lipoprotein cholesterol; SSNHL: Sudden sensorineural hearing loss; TC: Total cholesterol; TG: Triglycerides

\section{Acknowledgements}

Not applicable.

\section{Funding}

The study is supported by the Program for Fundamental Research of RAS (2018-2020), state registration number AAAA-A18-118012290366-9 (project № 18-7-8-7).

\section{Availability of data and materials}

The datasets used and analysed during the current study are available from the corresponding author on reasonable request.

\section{Authors' contributions}

ERB, YKY and JOO designed and supervised the project. NNP coordinated the blood samples collection and performed laboratory biochemical analyses. SGB performed audiological examinations. SGB, OEK and YKY participated in interpretation of the results of the audiological examinations. AMK contributed to the statistical analysis and interpretation of data and wrote the first draft of the paper. All authors contributed to the critically revision of the article and approved the final published version to be published

\section{Authors' information}

Not applicable.

\section{Ethics approval and consent to participate}

This study was conducted under the guiding principles of the Declaration of Helsinki and was approved by the ethics committee of Institute of Physiology of Komi Science Centre of the Ural Branch of the Russian Academy of Sciences, FRC Komi SC UB RAS.

Consent for publication

Not applicable.

\section{Competing interests}

The authors declare that they have no competing interests.

\section{Publisher's Note}

Springer Nature remains neutral with regard to jurisdictional claims in published maps and institutional affiliations.

\section{Author details}

${ }^{1}$ Institute of Physiology of Komi Science Centre of the Ural Branch of the Russian Academy of Sciences, FRC Komi SC UB RAS, 50 Pervomayskaya str, Syktyvkar 167982, Russia. ${ }^{2}$ St. Petersburg Research Institute of Ear, Throat, Nose and Speech, Ministry of Health of the Russian Federation, 9 Bronnitskaya str, St. Petersburg 190013, Russia. ${ }^{3}$ Medical Institute of Syktyvkar State University named after Pitirim Sorokin, Babushkina str., 11, Syktyvkar, Russia167001. ${ }^{4}$ Faculty of Health Sciences, NTNU, Norwegian University of Science and Technology, NTNU, NO-7491 Trondheim, Norway.

Received: 22 November 2018 Accepted: 10 March 2019

Published online: 15 March 2019

\section{References}

1. Stachler RJ, Chandrasekhar SS, Archer SM, Rosenfeld RM, Schwartz SR, Barrs DM, Brown SR, Fife TD, Ford P, Ganiats TG, Hollingsworth DB, Lewandowski CA, Montano JJ, Saunders JE, Tucci DL, Valente M, Warren BE, Yaremchuk $\mathrm{KL}$, Robertson PJ; American Academy of Otolaryngology-Head and Neck Surgery. Clinical practice guideline: sudden hearing loss. Otolaryngol Head Neck Surg. 2012;146 Suppl:1-35.

2. Schreiber BE, Agrup C, Haskard DO, Luxon LM. Sudden sensorineural hearing loss. Lancet. 2010;375:1203-11.

3. Marcucci R, Alessandrello Liotta A, Cellai AP, Rogolino A, Berloco P, Leprini E, Pagnini P, Abbate R, Prisco D. Cardiovascular and thrombophilic risk factors for idiopathic sudden sensorineural hearing loss. J Thromb Haemost. 2005;3: 929-34. 
4. Kuhn M, Heman-Ackah SE, Shaikh JA, Roehm PC. Sudden sensorineural hearing loss: a review of diagnosis, treatment, and prognosis. Trends Amplif. 2011;15:91-105.

5. Toubi E, Ben-David J, Kessel A, Halas K, Sabo E, Luntz M. Immune-mediated disorders associated with idiopathic sudden sensorineural hearing loss. Ann Otol Rhinol Laryngol. 2004;13:445-9.

6. Merchant SN, Adams JC, Nadol JB. Pathology and pathophysiology of idiopathic sudden sensorineural hearing loss. Otol Neurotol. 2005;26:151-60.

7. Masuda M, Kanzaki S, Minami S, Kikuchi J, Kanzaki J, Sato H, Ogawa K. Correlations of inflammatory biomarkers with the onset and prognosis of idiopathic sudden sensorineural hearing loss. Otol Neurotol. 2012;33:114250.

8. Chau JK, Lin JR, Atashband S, Irvine RA, Westerberg BD. Systematic review of the evidence for the etiology of adult sudden sensorineural hearing loss. Laryngoscope. 2010;120:1011-21.

9. Hoet $\mathrm{P}$, Lison D. Ototoxicity of toluene and styrene: state of current knowledge. Crit Rev Toxicol. 2008:38:127-70.

10. Brusis T. Sensorineural hearing loss after dull head injury or concussion trauma. Laryngorhinootologie. 2011;90:73-80.

11. Sauvaget E, Kici S, Kania R, Herman P, Tran Ba Huy P. Sudden sensorineura hearing loss as a revealing symptom of vestibular schwannoma. Acta Otolaryngol. 2005;125:592-5.

12. Cadoni G, Agostino S, Scipione S, Galli J. Low serum folate levels: a risk factor for sudden sensorineural hearing loss? Acta Otolaryngol. 2004;124: 608-11.

13. Guo Y, Zhang C, Du X, Nair U, Yoo TJ. Morphological and functional alterations of the cochlea in apolipoprotein $\mathrm{E}$ gene deficient mice. Hear Res. 2005;208:54-67.

14. Onal M, Elsurer C, Selimoglu N, Yilmaz M, Erdogan E, Bengi Celik J, Kal O, Onal O. Ozone prevents cochlear damage from ischemia-reperfusion injury in Guinea pigs. Artif Organs. 2017:41:744-52.

15. Kim JS, Lopez I, DiPatre PL, Liu F, Ishiyama A, Baloh RW. Internal auditory artery infarction: clinicopathologic correlation. Neurology. 1999:52:40-4.

16. Lee JS, Kim DH, Lee HJ, Kim HJ, Koo JW, Choi HG, Park B, Hong SK. Lipid profiles and obesity as potential risk factors of sudden sensorineural hearing loss. PLoS One. 2015:10:e0122496.

17. Xipeng L, Ruiyu L, Meng L, Yanzhuo Z, Kaosan G, Liping W. Effects of diabetes on hearing and cochlear structures. Journal Otology. 2013:8:82-7.

18. Rosen S, Olin P. Hearing loss and coronary heart disease. Arch Otolaryngol. 1965:82:236-43.

19. Lowry LD. Hyperlipoproteinemia: cause of sensorineural hearing loss? Trans Pa Acad Ophthalmol Otolaryngol. 1975;28:56-9.

20. Suckfüll M, Thiery J, Wimmer C, Mees K, Schorn K. Hypercholesteremia and hyperfibrinogenemia in sudden deafness. Laryngorhinootologie. 1997;76: 453-7.

21. Mohammed AA. Lipid profile among patients with sudden sensorineura hearing loss. Indian J Otolaryngol Head Neck Surg. 2014;66:425-8.

22. Aimoni C, Bianchini C, Borin M, Ciorba A, Fellin R, Martini A, Scanelli G, Volpato S. Diabetes, cardiovascular risk factors and idiopathic sudden sensorineural hearing loss: a case-control study. Audiol Neurotol. 2010;15: $111-5$

23. Kojima $Y$, Ito S, Furuya N. Hearing improvement after therapy for hyperlipidemia in patients with chronic-phase sudden deafness. Ann Otol Rhinol Laryngol. 2001;110:105-8.

24. Cai Q, Du X, Zhou B, Cai C, Kermany MH, Zhang C, Yoo T. Effects of simvastatin on plasma lipoproteins and hearing loss in apolipoprotein $E$ gene-deficient mice. ORL J Otorhinolaryngol Relat Spec. 2009;71:244-50.

25. Gratton MA, Wright CG. Alterations of inner ear morphology in experimental hypercholesterolemia. Hear Res. 1992;61:97-105.

26. Jones NS, Davis A. A retrospective case-controlled study of 1490 consecutive patients presenting to a neuro-otology clinic to examine the relationship between blood lipid levels and sensorineural hearing loss. Clin Otolaryngol Allied Sci. 2000;25:511-7.

27. Odeh OI, Kuti MA, Fasunla AJ, Nwaorgu OG. Sensorineural hearing loss and dyslipidemia: is there any relationship? West Afr J Med. 2015;34:27-31

28. Friedewald WT, Levy RI, Fredrickson DS. Estimation of the concentration of low-density lipoprotein cholesterol in plasma, without use of the preparative ultracentrifuge. Clin Chem. 1972;18:499-502.

29. Dobiasova M, Frohlich J. The plasma parameter log (TG/HDL-C) as an atherogenic index: correlation with lipoprotein particle size and esterification rate in apoB-lipoprotein-depleted plasma (FER(HDL)). Clin Biochem. 2001:34:583-8.

30. Berg JE, Høstmark AT. Cardiovascular risk determination: discrepancy between total cholesterol evaluation and two compound laboratory indices in Norway. J Epidemiol Community Health. 1994;48:338-43.

31. Friedland DR, Cederberg C, Tarima S. Audiometric pattern as a predictor of cardiovascular status: development of a model for assessment of risk. Laryngoscope. 2009;119:473-86.

32. Weng $T$, Devine EE, Xu H, Yan Z, Dong P. A clinical study of serum lipid disturbance in Chinese patients with sudden deafness. Lipids Health Dis. 2013:12:95

33. Kaneva AM, Potolitsyna NN, Bojko ER, Odland JO. The apolipoprotein B/ apolipoprotein A-I ratio as a potential marker of plasma atherogenicity. Dis Markers. 2015;2015:591454.

34. Frederiksen TW, Ramlau-Hansen CH, Stokholm ZA, Brødsgaard Grynderup M, Hansen AM, Lund SP, Medom Vestergaard J, Kristiansen J, Bonde JP, Kolstad HA. Atherogenic risk factors and hearing thresholds. Audiol Neurotol. 2014; 19:310-8.

35. Lu YY, Jin Z, Tong BS, Yang JM, Liu YH, Duan M. A clinical study of microcirculatory disturbance in Chinese patients with sudden deafness. Acta Otolaryngol. 2008;128:1168-72.

36. Nakashima $T$, Naganawa $S$, Sone $M$, Tominaga M, Hayashi $H$, Yamamoto $H$, Liu X, Nuttall AL. Disorders of cochlear blood flow. Brain Res Brain Res Rev. 2003:43:17-28

37. Saito T, Sato K, Saito H. An experimental study of auditory dysfunction associated with hyperlipoproteinemia. Arch Otorhinolaryngol. 1986;243:242-5

38. Singh RB, Mengi SA, Xu YJ, Arneja AS, Dhalla NS. Pathogenesis of atherosclerosis: a multifactorial process. Exp Clin Cardiol. 2002;7:40-53.

39. Lamarche B, Tchernof A, Moorjani S, Cantin B, Dagenais GR, Lupien PJ, Després JP. Small, dense low-density lipoprotein particles as a predictor of the risk of ischemic heart disease in men. Prospective results from the Québec cardiovascular study. Circulation. 1997:95:69-75.

40. Linn S, Fulwood R, Carroll M, Brook JG, Johnson C, Kalsbeek WD, Rifkind BM. Serum total cholesterol: HDL cholesterol ratios in US white and black adults by selected demographic and socioeconomic variables (HANES II). Am J Public Health. 1991:81:1038-43.

41. Contois JH, McNamara JR, Lammi-Keefe CJ, Wilson PW, Massov T, Schaefer EJ. Reference intervals for plasma apolipoprotein A-I determined with a standardized commercial immunoturbidimetric assay: results from the Framingham offspring study. Clin Chem. 1996;42:507-14.

42. Contois JH, McNamara JR, Lammi-Keefe CJ, Wilson PW, Massov T, Schaefer EJ. Reference intervals for plasma apolipoprotein B determined with a standardized commercial immunoturbidimetric assay: results from the Framingham offspring study. Clin Chem. 1996;42:515-23.

43. Walldius $\mathrm{G}$. The apoB/apoA-I ratio is a strong predictor of cardiovascular risk In: Frank S, Kostner G, editors. Lipoproteins in health and diseases. Rijeka (Croatia): InTech; 2012. p. 95-148.

44. Mahley RW, Innerarite TL, Rall SC, Weisgraber K.H. Plasma lipoproteins: apolipoprotein structure and function. J Lipid Res 1984;25:1277-1294.

45. National Cholesterol Education Program (NCEP). Expert Panel on Detection, Evaluation, and Treatment of High Blood Cholesterol in Adults (Adult Treatment Panel III). Third Report of the National Cholesterol Education Program (NCEP) Expert Panel on Detection, Evaluation, and Treatment of High Blood Cholesterol in Adults (Adult Treatment Panel III) Final Report. Circulation. 2002;106:3143-421.

Ready to submit your research? Choose BMC and benefit from:

- fast, convenient online submission

- thorough peer review by experienced researchers in your field

- rapid publication on acceptance

- support for research data, including large and complex data types

- gold Open Access which fosters wider collaboration and increased citations

- maximum visibility for your research: over $100 \mathrm{M}$ website views per year

At BMC, research is always in progress.

Learn more biomedcentral.com/submissions 